\title{
The Baby-Friendly Hospital Initiative: increasing breastfeeding and decreasing infant mortality in Brazil
}

Osvaldinete Lopes de Oliveira Silva 1

Marina Ferreira Rea 2

Sonia Isoyama Venâncio 3

Gabriela dos Santos Buccini 4

\footnotetext{
1 Faculdade de Ciências Farmacêuticas, Alimentos e Nutrição. Universidade Federal de Mato Grosso do Sul. Av. Costa e Silva. Cidade Universitária. Campo Grande, MS, Brasil. CEP: 79.070-900. E-mail: olinete@usp.br

2 Programa de Pós-graduação em Nutrição. Faculdade de Saúde Pública. Universidade de São Paulo. São Paulo, SP, Brasil.

3 Instituto de Saúde da Secretaria Estadual de Saúde de São Paulo. São Paulo, SP, Brasil.

4 Yale School of Public Health. Social behavior Science. New Haven, Connecticut United States.
}

\begin{abstract}
Objectives: to estimate the population attributable fraction of preventable infant mortality rates due to changes in breastfeeding $(B F)$ indicators attributable to the Baby Friendly Hospital Initiative (BFHI).

Methods: an estimate on the impact of BFHI in reducing infant mortality with an inferential level of plausibility, using secondary data from the II Breastfeeding Prevalence Survey of 2008. Initially, the effect of BFHI on breastfeeding in the first hour of life, exclusive breastfeeding, and any breastfeeding based on the prevalence of the outcomes among infants born in BFHI or non-BFHI was calculated. Second, the population attributable fraction of nonbreastfeeding was estimated for late neonatal mortality, mortality by all causes and infant mortality by infections, for BFHI and non-BFHI, and the number of potentially avoidable deaths if all children were born in BFH.

Results: reduction of $4.2 \%$ of late neonatal deaths due to the increase in $B F$ prevalence in the first hour, as provided by BFHI. BFHI potentially contributed with $3.5 \%$ of all-cause deaths and $4.2 \%$ of deaths from infection by BF promotion in infants below 6 months.

Conclusions: the reduction of mortality in children between 7 and 180 days in 2008 potentially attributable to BFHI through the promotion of BF indicators reinforces the importance of strengthening and expanding this initiative in Brazil to ultimately enhance child survival.
\end{abstract}

Key words Infant mortality, Breastfeeding, Child health, BFHI

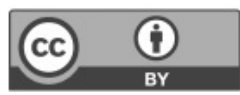




\section{Introduction}

From 1990 to 2016, while infant mortality rate decreased by $52.3 \%$ worldwide, it decreased $73.6 \%$ in Brazil, reducing from 53 to 14 infant deaths per 1,000 live births. However, as it is a strong indicator of the living conditions and health inequities of a population, it remains to be regarded as a Public Health concern. At the same time, the neonatal mortality rate was reduced by $48.6 \%$ and $69 \%$, in the world and in Brazil, respectively. Meanwhile, social disparities persist and result in the increase of the number of deaths of children in situations of social vulnerability. 1

Breastfeeding stands out as the single most effective practice among factors that help to reduce infant mortality, with the potential to prevent 823,000 deaths each year in children under five years of age worldwide, in addition to reducing the risk of acute and chronic diseases and promoting child growth and development; this effect is enhanced when breastfeeding starts within the first hour after birth and exclusively practiced in the first 6 months of life.2-6 Data from studies conducted in São Paulo on breastfeeding impact on infant mortality estimated mortality rates that could be avoided by breastfeeding exceeded $60 \%$ for respiratory infection.?

However, despite the strong evidence on benefits of exclusive breastfeeding for the first six months of life, national and global prevalence remain below the $50 \%$ goal recommended by the World Health Organization (WHO) for 2025.4,5,8

Many strategies aiming at the promotion, protection and support of breastfeeding have been implemented in Brazil from the 80's and resulted in positive effects on all breastfeeding indicators. ${ }^{9}$ According to National Demographic and Health Survey (NDHS), the rate of breastfeeding in the first hour of life (BFFHL) was $43 \%$ in 2006; in 2008, the II Breastfeeding Prevalence Survey (II BFPS) found a $67.1 \%$ rate of BFFHL, 10 while, more recently, the National Born Survey in Brazil, which was held in a sample of Brazilian hospitals and, therefore, with less risk of recall bias than previous surveys, showed a national prevalence of $56 \% .^{11}$ From 1975 to 2008 , the median duration of breastfeeding increased from 2.5 to 11.3 months, and exclusive breastfeeding for infants under six months increased from $3.1 \%$ to $41.0 \%$, which, although it has increased by 14 times, is still lower than expected. ${ }^{10,12}$

Among the actions implemented to promote breastfeeding, the Baby-Friendly Hospital Initiative (BFHI) stands out among the most effective actions to improve BFFHL rates, EBF, predominant breastfeeding (PBF) and any breastfeeding (ABF). 13-15 The BFHI was created by WHO and the United Nations Children's Fund in the early 90's with the aim of reducing infant mortality by promoting breastfeeding. In 2016, 10\% of global births occurred in BFHs, ranging from $35 \%$ in Europe to $5 \%$ in Africa, and $15 \%$ in Latin America and the Caribbean. 5,8 In Brazil, there were 326 accredited hospitals in 2016 corresponding to a $23.4 \%$ coverage of births in the country. $5,8,16$

Although the effectiveness of BFHI in raising breastfeeding rates is well established in the literature, 13-15 its potential effect in reducing infant deaths is still poorly understood. Considering the importance of impact studies and estimates to evaluate health policies and actions, the purpose of this analysis was to estimate the population attributable fraction of infant mortality by changes in breastfeeding indicators in Brazil due to BFHI.

\section{Methods}

The study used estimates on the impact of BFHI in reducing infant mortality with an inferential level of plausibility, based on population attributable fraction (PAF). PAF is capable of measuring the effect of elimination of the risk factor for a particular outcome, by measuring how much the occurrence of the outcome can be decreased if the risk factor is eliminated and therefore it allows quantifying the effect of a preventive strategy in Public Health.17-19

The analyses used two sources of secondary data, one for data collection on breastfeeding prevalence in children born in Baby-Friendly Hospitals $(\mathrm{BFH})$ or non-Baby-Friendly Hospitals (nBFH) and another for national data on infant mortality.

The breastfeeding prevalence among children born in BFH and $\mathrm{nBFH}$ were obtained from the II Breastfeeding Prevalence Survey (II BFPS), carried out in Brazil, in 2008. The BFPS is a national survey conducted in all Brazilian capitals and the Federal District on infant feeding practices and it involves infants under one year of age who attended national multi-vaccination campaigns. The research protocol of the II BFPS was approved by the Ethics Committee of the Health Institute (001/2008 Protocol from May 06, 2008), after consulting the National Research Ethics Committee.

The participants of the II BFPS were selected according to the number of vaccination centers and the number of children immunized in each center in the previous year. The sample was defined in two stages. In the first stage, vaccination centers were 
drawn, while a systematic draw set the order of children to be vaccinated in the second stage. The instrument used for data collection included characteristics of children and their mothers, whether the birth had been in $\mathrm{BFH}$ or $\mathrm{nBFH}$ and food consumption of the child in the past 24 hours. 10 Only infants under six months of age $(n=18,929)$ were included in this analysis, of which $34.1 \%$ were born in a BFH and half $(50.7 \%)$ were delivered vaginally. At the time of the interview, $71.4 \%$ of mothers were $20-35$ years old, $38.5 \%$ of them studied up to nine years and only $14.7 \%$ of mothers worked outside home. The sample of BFPS was designed to represent mothers and children living in Brazilian state capitals and the Federal District. 10,12

National data on infant mortality for 2008 from DATASUS, which is a system of the Ministry of Health, were used with the following three mortality indicators in order to calculate the number of preventable deaths: (A) Late neonatal mortality rate, which is defined as deaths occurring from 7 to 27 days of life. This study chose to use only the deaths that occurred during this period due to the strong influence of perinatal factors in early neonatal mortality (deaths occurring from 0 to 6 days of life)]; (B) All-cause mortality rate in the period from 7 days to 180 days of life; and (c) Infection mortality rate in the period from 7 days to 180 days of life.

Data analysis consisted of two stages that are outlined in Figure 1. The first stage aimed to identify the association between a birth in a BFH and breastfeeding and consisted of two steps. The first step (1a) obtained the prevalence of three breastfeeding indicators, according to birth in $\mathrm{BFH}$ or $\mathrm{nBFH}$. In order to ensure representativeness of the prevalence of breastfeeding indicators, the indicators were obtained taking into account the complexity of the sample of II BFPS, considering the sampling weight of each capital. In the second step (1b), the percentage difference in the prevalence of breastfeeding at birth in $\mathrm{BFH}$ was calculated as follows:

\section{BFH prevalence $-\mathrm{nBFH}$ prevalence $\mathrm{X} 100$ nBFH prevalence}

The second stage was designed to estimate the attributable fraction of the BFHI in reducing infant mortality, mediated by an increase in breastfeeding rates. To this end, the first step of the second stage (2a) was used to calculate the population attributable fraction of non-breastfeeding for children born in nBFH (PAFnBFH) and for children born in BFH (PAFBFH) as well, considering the three mortality indicators selected. PAF was calculated in this analysis as suggested by Rezende and Eluf-Neto. 18

$$
\mathrm{PAF}=\mathrm{Pex}(\mathrm{RR}-1) / \operatorname{Pex}(\mathrm{RR}-1)+1
$$

Where RR is the relative risk of mortality of those exposed compared to those who were not exposed to it. The relative risk (RR) were obtained from meta-analysis on the effect of breastfeeding on mortality indicators described in the literature (Table 1) and Pex is related to the exposure prevalence obtained from data of the II BFPS.

Two conditions were regarded as exposure factors: the non-breastfeeding in the first hour of life (NBFFHL) and non-breastfeeding of children under 6 months of age (NBF). Three outcomes were analyzed, namely, the (i) late neonatal mortality rate mediated by the exposure to NBFFHL; (ii) all-cause mortality rate and (iii) infection mortality rate mediated by exposure to NBF compared to children in $\mathrm{EBF}$, both in children under 6 months of age.

The second step ( $2 b)$ estimated the number of infant deaths attributable to non-breastfeeding applying the estimated PAFs (PAFnBFH and PAFBFH) to infant mortality rate data from 2008. Therefore, it was possible to obtain the estimated number of preventable deaths by promoting breastfeeding, if all the children were born in a BFH, by subtracting the deaths attributable to PAFnBFH from the PAFBFH data.

Statistical analysis was performed in StataSE 14.1 software and Excel ${ }^{\circledR}$. The comparison between proportions was performed using a Chi-square test and the calculation of PAFs confidence intervals was performed by replacement method, as proposed by Daly20and subsequently applied in such studies. 17

\section{Results}

Breastfeeding rates among children who were born in a BFH (34.1\% of 18,929 children under 6 months of age) were significantly higher in all indicators in the sample obtained from the II BFPS data. Table 2 shows the prevalence of the three breastfeeding indicators investigated for children who were born in $\mathrm{BFH}$ and NBFH. There was an increase of $11.7 \%$, $7.9 \%$ and $2.1 \%$ for BFFHL, EBF and ABF, respectively, for those who were born in a BFH.

When PAFs in infant mortality rate due to nonbreastfeeding were calculated, it was observed that if all children were born in a BFH, the mortality fraction attributable to non-breastfeeding would be lower for all outcomes due to higher breastfeeding rates provided by the BFHI (Table 3 ). 
Figure 1

Description of the stages of analysis to estimate the reduction in infant mortality drove by breastfeeding promoted by the Baby-Friendly Hospital Initiative (BFHI).

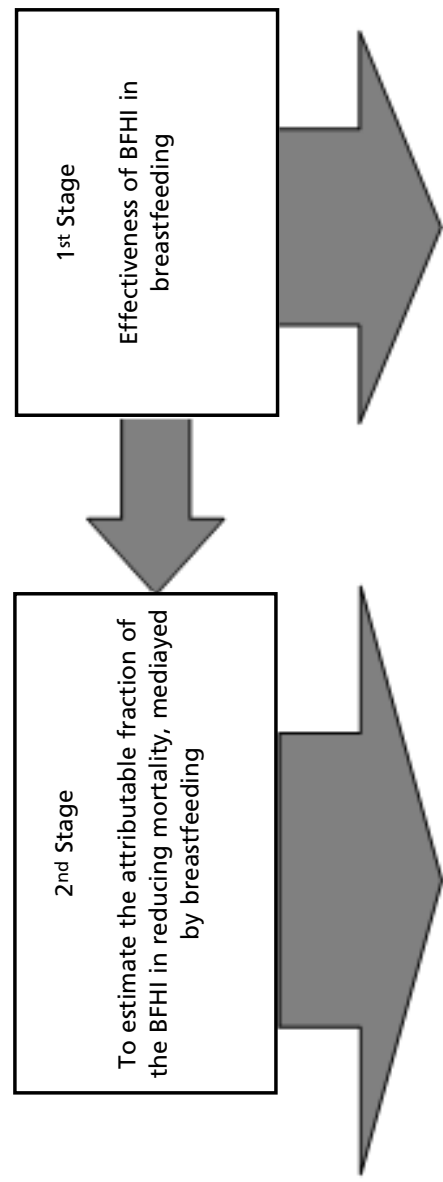

(1a) Birth prevalence in BFH and nBFH (BFFHL, EBF $<6$ months, ABF $<6$ months)

Source: II BFPS, 2008

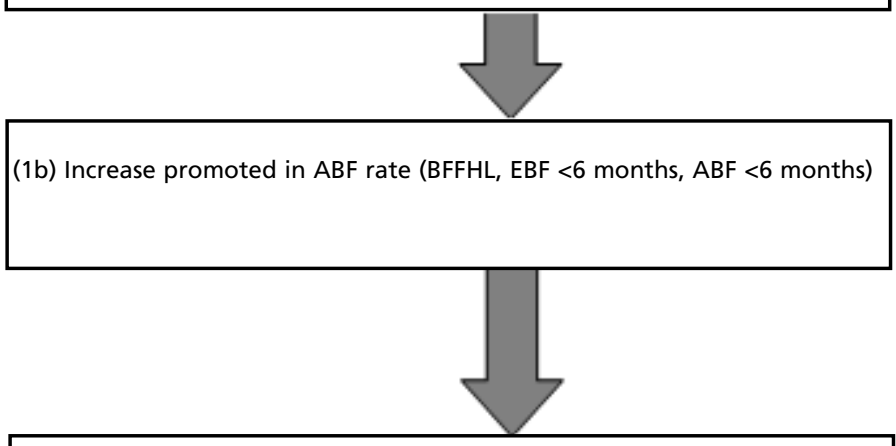

(2a) Calculation of the attributable fraction of non-breastfeeding for infant mortality rate in $\mathrm{BFHs}$ and $\mathrm{nBFH}$

i. Late neonatal mortality rate

ii. All-cause mortality rate

iii. Infection mortality rate

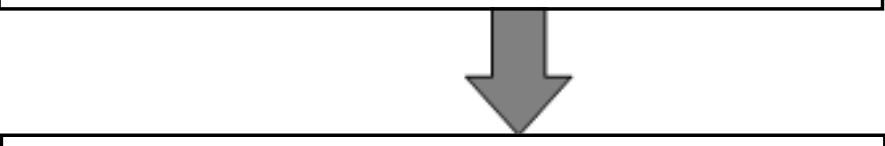

(2b) Estimated number of deaths prevented by BFHI

Baby-Friendly Hospital (BFH); non-Baby-Friendly Hospital (NBFH); Breastfeeding in the first hour of life (BFFHL); Exclusive breastfeeding (EBF); Any breastfeeding (ABF); II Breastfeeding Prevalence Survey (II BFPS).

\section{Table 1}

Effect of non-breastfeeding on infant mortality indicators, according to meta-analysis.

\begin{tabular}{llll}
\hline Indicators & Relative risk (Cl95\%) & Reference
\end{tabular}

Neonatal mortality rate among children from 7-27 days of life who

breastfed in the first hour after birth.

All-cause mortality rate for children from 0-5 months of age who were 
Table 4 estimates how many deaths would be prevented if all children were born in a $\mathrm{BFH}$ when PAFnBFH and PAFBFH are applied to the number of infant deaths that occurred in 2008 in Brazil.
There was a $4.2 \%$ reduction in mortality due to BFHI for late neonatal mortality rate, in addition to a $3.5 \%$ reduction for all-cause mortality rate and a $4.2 \%$ reduction in the infection mortality rate.

Table 2

Prevalence and percentage difference in breastfeeding indicators considering birth in non-Baby-Friendly Hospital (nBFH) or Baby-Friendly Hospital (BFH). Brazilian capitals and the Federal District, 2008.

\begin{tabular}{|c|c|c|c|c|c|c|}
\hline \multirow[t]{2}{*}{ Breastfeeding indicators } & \multicolumn{2}{|c|}{ nBFH1 } & \multicolumn{2}{|c|}{ BFH1 } & \multirow[t]{2}{*}{ Difference Observed2 } & \multirow[t]{2}{*}{$p^{*}$} \\
\hline & $n$ & $\%$ & $\mathrm{n}$ & $\%$ & & \\
\hline \multicolumn{7}{|l|}{ BFFHL } \\
\hline$(n=16,570)$ & 7,035 & 63.0 & 4,396 & 70.4 & 11.7 & $<0.05$ \\
\hline \multicolumn{7}{|l|}{ EBF ( $<6$ months) } \\
\hline$(n=16,632)$ & 4,277 & 40.5 & 2,652 & 43.7 & 7.9 & $<0.05$ \\
\hline \multicolumn{7}{|l|}{ ABF (<6 months) } \\
\hline$(n=17,327)$ & 9,712 & 87.7 & 5,669 & 89.5 & 2.1 & $<0.05$ \\
\hline
\end{tabular}

1 Breastfeeding prevalence has been calculated considering the sampling weight of the complex sample of the II Breastfeeding Prevalence Survey.

2 Difference attributed to the Baby-Friendly Hospital Initiative on breastfeeding indicators.

*Chi-Squared Test

$B F F H L=$ Breastfeeding in the first hour of life; $E B F=$ Exclusive breastfeeding; $A B F=$ Any breastfeeding.

\section{Table 3}

Population attributable fraction (PAF) of infant mortality associated with non-breastfeeding considering births in nonBaby-Friendly Hospital (nBFH) and Baby-Friendly Hospital (BFH). Brazilian capitals and the Federal District, 2008.

Mortality Indicators

PAF of non-breastfeeding (Cl95\%)

\begin{tabular}{cc}
\hline $\mathrm{nBFH}$ & $\mathrm{BFH}$ \\
\hline $27.4(12.9-41.7)$ & $23.2(10.6-36.4)$ \\
$62.2(38.7-80.2)$ & $58.7(35.2-77.7)$ \\
$49.0(21.2-73.5)$ & $44.8(18.8-70.5)$
\end{tabular}

\# Mortality of children from 7 to 27 days of age not breastfed in the first hour compared to those breastfed in the first hour.

* Mortality of children from 7 days to 5 months of age not breastfed compared with children of the same age on exclusive breastfeeding.

NBFFHL = non-breastfeeding in the first hour of life; NBF = non-breastfeeding. 
Estimate of deaths attributable to non-breastfeeding among children born in non-Baby-Friendly Hospital (NBFH), in Baby-Friendly Hospital (BFH) and potentially preventable deaths by the Baby Friendly Hospital Initiative (BFHI). Brazilian capitals and the Federal District, 2008.

\begin{tabular}{|c|c|c|c|c|c|c|c|}
\hline \multirow[t]{2}{*}{ Indicators } & \multirow[t]{2}{*}{$\begin{array}{l}\text { Deaths } \\
\text { in } 2008\end{array}$} & \multirow[t]{2}{*}{$\begin{array}{l}\text { PAF } \\
\text { nBFH }\end{array}$} & \multirow[t]{2}{*}{$\begin{array}{l}\text { Deaths } \\
\text { attributable } \\
\text { to } \mathrm{nBFH}\end{array}$} & \multirow[t]{2}{*}{$\begin{array}{l}\text { PAF } \\
\text { BFH }\end{array}$} & \multirow[t]{2}{*}{$\begin{array}{c}\text { Deaths } \\
\text { attributable } \\
\text { to } \mathrm{BFH}\end{array}$} & \multicolumn{2}{|c|}{$\begin{array}{l}\text { Deaths } \\
\text { preventable } \\
\text { with BFHI }\end{array}$} \\
\hline & & & & & & $\mathrm{n}$ & $\%$ \\
\hline Late neonatal mortality rate (NBFFHL)\# & 6,9931 & 27.4 & 1,916 & 23.2 & 1,622 & 294 & 4.2 \\
\hline All-cause mortality rate $(\mathrm{NBF}<6 \mathrm{~m}) *$ & 17,2162 & 62.2 & 10,708 & 58.7 & 10,106 & 602 & 3.5 \\
\hline Infection mortality rate $(\mathrm{NBF}<6 \mathrm{~m})$ * & $17,216^{2}$ & 49.0 & 8,436 & 44.8 & 7,713 & 723 & 4.2 \\
\hline
\end{tabular}

1 Deaths of children from 7 to 27 days of life, in 2008. Source: DATASUS

(http://tabnet.datasus.gov.br/cgi/tabcgi.exe?sim/cnv/inf10uf.def)

2 Deaths of children from 7 days to 5 months of life, in 2008. Source: DATASUS

(http://tabnet.datasus.gov.br/cgi/tabcgi.exe?sim/cnv/inf10uf.def)

\# Mortality of children from 7 to 27 days of age not breastfed in the first hour compared to those breastfed in the

first hour.

* Mortality of children from 7 days to 5 months of age not breastfed compared with children of the same age on exclusive breastfeeding.

PAF= Population attributable fraction; NBFFHL = non-breastfeeding in the first hour of life; NBF = non-breastfeeding.

\section{Discussion}

Results indicate in an unprecedented way the potential impact of BFHI in reducing infant mortality in Brazil due to the increase it provides in the prevalence of different breastfeeding indicators and what it means to be born in a Baby-Friendly Hospital in terms of lives saved. The prevalence of breastfeeding in the first hour of life was $11.7 \%$ higher among those who were born in a BFH when compared to those who were not born in a BFH. Similarly, the EBF in children under six months of age was $7.9 \%$ higher among infants who were born in a BFH. This higher breastfeeding prevalence would result in a 3.5 to $4.2 \%$ reduction of infant deaths among children from 7 to 180 days of age, if all children were born in a BFH.

The effect noticed in the reduction of late neonatal mortality rate due to a greater prevalence in the BFFHL in children born in a BFH reinforces the evidence of this practice as an important protective factor for child survival.6,8,21,22 In a randomized trial with 10,947 children in Ghana, Edmond et al.22 showed the protective effect of early breastfeeding by noticing that $22 \%$ of neonatal deaths could be prevented if breastfeeding was initiated in the first hour of life, and another $16 \%$ could be avoided if all children were breastfed on the first day. The lower reduction found in our study - in spite of the differences from an African country to a Latin America country - may be explained by the fact that this study is not a direct analysis of the effect of breastfeeding on mortality rate, but an estimate of the effect provided by the BFHI mediated by the breastfeeding promotion.

At the same time, it highlights the importance of this policy as one of the most effective strategies to foster the BFFHL by advocating the postponement of routine care of the newborn, providing an opportunity for skin-to-skin contact soon after birth, thus favoring the early initiation of breastfeeding. $6,11,14,23$ WHO recommends this procedure to be incorporated into national quality standards for maternal, newborn and child health care in order to prevent infant deaths. 5,8

The reduction of 602 deaths from all causes and 723 deaths from infection in children under 6 months of age was identified even with a little percentage difference in any breastfeeding promoted by the BFHI (2.1\%). Our findings corroborate the results described in the literature. $2,7,4$ Lamberti et al. ${ }^{2}$ noticed that non-breastfed children had 4.7 times higher risk of death from all causes and 9.5 higher risk to experience death by pneumonia.2,3,4,8 In a systematic review and meta-analysis, Victora et al. 4 showed a protection against the risk of death from 
infectious disease conferred by any breastfeeding, and especially by EBF, which is a protection that extends to the second year of life. Thus, the increase in breastfeeding rates should be among top priorities in order to reduce infant deaths, justifying investments in public policies that promote breastfeeding. $4,5,8$

Therefore, this evidence supports the original purpose of the BFHI to contribute to the reduction of infant mortality, given the association between the BFHI and higher breastfeeding rates. ${ }^{13-15}$ Despite the effectiveness of BFHI in raising the prevalence of breastfeeding, the effect observed in this study is more discreet when compared to international studies. An almost experimental community trial carried out in 54 municipalities in Norway including 2,030 children showed that BFHI increased the probability of EBF by $33 \%$ in children under six months of age. 24

A recent systematic review with meta-analysis found that the BFHI contributed to increase by $20 \%$ and $49 \%$ the BFFHL and the EBF, respectively, in the first six months of age, in addition to an increase of $66 \%$ in any breastfeeding. 14 In a review of studies from 19 countries, Pérez-Escamilla et al.15 found that the BFHI has a positive effect on breastfeeding outcomes in short, medium and long term, confirming the results of the PROBIT trial, which was a pioneer in showing the effectiveness of the BFHI. 13

However, it is known that the occurrence of this effect is subject to compliance with the 'Ten Steps to Successful Breastfeeding', which is the basis of the Initiative. According to Pérez-Escamilla et al.,15 there is a dose-response relationship between the number of steps of the BFHI in which women are exposed and the likelihood to improve breastfeeding outcomes. DiGirolamo25 noticed that mothers who haven't experienced any of the steps of the BFHI were 13 times more likely to stop breastfeeding early. The step 10 (refers mothers to breastfeeding support groups in primary care) seems to be essential to sustain the effects of the BFHI in long-term breastfeeding as it strengthens breastfeeding support and promotion actions in primary care. 15,26

With respect to Brazil, data from the online monitoring of BFHI, which is conducted annually by the Ministry of Health, indicate an increase in the average compliance rate of the Ten Steps, ranging from $56.8 \%$ in 2011 to $86.8 \%$ in 2015 , with step 4 (skin-to-skin contact) increasing from $45 \%$ to $65 \%$ over the same period. 16 However, national studies carried out over the 25 years of the BFHI in Brazil highlighted the difficulties related to the compliance of the Ten Steps in accredited hospitals. ${ }^{26-29}$ Therefore, this may be a major factor that contributed to the lower effectiveness of the BFHI in reducing infant mortality through breastfeeding promotion in this study.

WHO and PAHO recent reports recognizes that the BFHI faces many challenges in terms of sustainability, funding and competing priorities worldwide. The resistance to change and lack of identification with the Initiative are among the main challenges, as well as problems related to human resources, such as staff turnover and lack of training, and violations of the International Code of Marketing of Breastmilk Substitutes. There are warnings that attention to this policy has been decreasing over time, and that it need to be revitalized, given its importance in promoting breastfeeding to save lives. 5,8

A study noted that the implementation of the $\mathrm{BFHI}$ in Brazil is a comprehensive change process that influences different aspects of an institution, including technological and structural changes and in particular cultural changes, in addition to the resistance to change and lack of ownership of the initiative by physicians and managers. 30 This is required to raise awareness and to the humanization of the professionals involved in the implementation of appropriate practices of delivery/birth and breastfeeding. These issues require a confrontation and help to explain the challenges to meet the criteria required by the Initiative, which can determine its impact on reducing child mortality.

Although the estimates of prevalence of breastfeeding indicators have been obtained from a representative sample of children in Brazilian state capitals and the Federal District, it is not possible to attest the compliance of BFH with respect to the Ten Steps at the time of the completion of the study. Thus, the BFHI impact estimates mediated by the increased breastfeeding prevalence may be underestimated, which is a limitation of this study. However, the PAF approach consists of a viable and recommended methodology that should be repeated to assess the impact of public health interventions. 17-19

We understand that the data generated by this study, despite the aforementioned limitation, provide an important contribution in favor of the expansion of this policy in Brazil.

The BFHI contributed to reducing infant deaths in children from 7 to 180 days of age in Brazil in 2008. The reduction of infant mortality that is potentially attributable to BFHI, due to its effect increasing the prevalence of different breastfeeding indicators, justifies and reinforces the importance of national investments in strengthening, expanding 
and sustaining this public policy.

\section{References}

1. UNICEF (Fundo das Nações Unidas para a Infância) Levels \& Trends in Child Mortality: Report 2017 Estimates developed by the UN inter-agency group for child mortality estimation. New York: UNICEF/WHO 2017. [acesso em 26 fev 2018]. Disponível em: http://childmortality.org/files_v21/download/IGME\%20report\%20 2017\%20child\%20mortality\%20final.pdf

2. Lamberti LM, Zakarija-Grković I, Walker CL, Theodoratou E, Nair H, Campbell H. Breastfeeding for reducing the risk of pneumonia morbidity and mortality in children under two: a systematic literature review and meta-analysis. BMC Public Health. 2013; 13 (Suppl. 3): S18.

3. Sankar MJ, Sinha B, Chowdhury R, Bhandari N, Taneia S, Martines J, Bahl R. Optimal breastfeeding practices and infant and child mortality: a systematic review and metaanalysis. Acta Pediatr. 2015; 104 (3): 3-13.

4. Victora CG, Bahl R, Barros AJD, França GVA, Horton S, Krasevec $J$ et al. Breastfeeding in the 21 st century: epidemiology, mechanisms, and lifelong effect. Lancet. 2016; 387 (10017): 475-90

5. WHO (World Health Organization). National Implementation of the Baby-friendly Hospital Initiative, Geneva; 2017. [acesso em 10 de set 2017]. Disponível em: http://www.who.int/nutrition/publications/infantfeeding/bfh i-national-implementation2017/en/

6. Khan J, Vesel L, Bahl R, Martines JC. Timing of Breastfeeding Initiation and Exclusivity of Breastfeeding During the First Month of Life: Effects on Neonatal Mortality and Morbidity-A Systematic Review and Metaanalysis. Matern Child Health J. 2015; 19: 468-79

7. Escuder MM, Venâncio SI, Pereira JCS. Estimativa de impacto da amamentação sobre a mortalidade infantil. Rev Saúde Pública. 2003; 37 (3); 319-25.

8. OPAS (Organización Panamericana de la Salud). La Iniciativa hospital amigo del niño en América Latina y el Caribe: Estado actual, retos y oportunidades. Washington, DC: OPS, 2016.

9. Rea MF. Reflexões sobre a amamentação no Brasil: de como passamos a 10 meses de duração. Cad Saúde Pública. 2003; 19 (Supl. 1): S37-S45.

10. Brasil. Ministério da Saúde. II Pesquisa de Prevalência de Aleitamento Materno nas Capitais Brasileiras e Distrito Federal. Brasília, DF; 2009. 108p. [acesso em 26/02/2018] Disponível em: http://bvsms.saude.gov.br/bvs/publicacoes/pesquisa_prevalencia_aleitamento_materno.pdf

11. Carvalho ML, Boccolini CS, Oliveira MIC, Leal MC. The baby-friendly hospital initiative and breastfeeding at birth in Brazil: a cross sectional study. Reprod Health. 2016; 13 (3): 119 .

12. Venâncio SI, Saldiva SRDM, Monteiro CA. Tendência secular da amamentação no Brasil. Rev Saúde Pública. 2013; 47 (6): 1205-8.
13. Martens PJ. What do Kramer's Baby-Friendly Hospital Initiative PROBIT studies tell us? A review of a decade of research. J Hum Lact. 2012; 28 (3): 335-42.

14. Sinha B, Chowdhury R, Sankar MJ, Martines J, Taneia S, Mazumder $\mathrm{S}$ et al. Interventions to improve breastfeeding outcomes: a systematic review and meta-analysis. Acta Pædiatr. 2015; 104: 114-35.

15. Pérez-Escamilla RP, Martinez JL, Segura-Pérez S. Impact of the Baby-friendly Hospital Initiative on breastfeeding and child health outcomes: a systematic review. Matern Child Nutr. 2016; 12 (3): 402-17.

16. Cruz NS. Evolução do grau de cumprimento dos critérios preconizados pela Iniciativa Hospital Amigo da Criança no Brasil. In: IBFAN. Anais do XIV Encontro Nacional de Aleitamento Materno; 2016, 22 a 25 de nov; Florianópolis, Brasil. 2016. p.528.

17. McIsaac KE; Moineddin R; Matheson FI. Breastfeeding as a means to prevent infant morbidity and mortality in Aboriginal Canadians: A population prevented fraction analysis. Can J Public Health. 2015; 106 (4): 217-222.

18. Rezende LFM, Eluf-Neto J. Fração atribuível populacional: planejamento de ações de prevenção de doenças no Brasil. Rev Saúde Pública. 2016; 50: 30.

19. Camey AS, Agrononik M, Radaelli J, Hirokata NV. Fração atribuível populacional. Rev HCPA. 2010; 30 (1): 77-85.

20. Daly LE. Confidence limits made easy: Interval estimation using a substitution method. Am J Epidemiol. 1998; 147(8): 783-90.

21. Debes AK, Kohli A, Walker N, Edmond K, Mullany LC. Time to initiation of breastfeeding and neonatal mortality and morbidity: a systematic review. BMC Public Health. 2013; 13 (Suppl. 3): S19.

22. Edmond KM, Zandoh C, Quigley MA, Amenga-Etego S, Owusu-Agyei S, Kirkwood BR. et. Delayed breastfeeding initiation increases risk of neonatal mortality. Pediatrics. 2006; 117 (3): e380-6.

23. Venâncio SI, Saldiva SR, Escuder MM, Giugliani ER. The baby-friendly hospital initiative shows positive effects on breastfeeding indicators in Brazil. J Epidemiol Community Health. 2012; 66 (10): 914-8.

24. Baeruk A, Langsrud O, Loland BF, Tufte E, Tylleskar T, Fretheim A. Effectiveness of Baby-friendly community health services on exclusive breastfeeding and maternal satisfaction: a pragmatic trial. Matern Child Nutr. 2016; 12 : 428-39.

25. DiGirolamo AM, Grummer-Strawn LM, Fein SB. Effect of maternity-care practices on breastfeeding. Pediatrics. 2008; 122 (Suppl. 2): 43-9.

26. Passanha A, Benício MHD, Venâncio SI, Reis MCG. Influência do apoio ao aleitamento materno oferecido pelas maternidades. Rev Saúde Pública. 2015; 49: 85. 
27. Ortiz PN, Rolim RB, Souza MFL, Soares PL, Vieira TO, Vieira GO, Lyra PPR, Silva LR. Comparação das práticas de amamentação em hospitais IHAC e não credenciados em Salvador, Bahia. Rev Bras Saúde Matern Infant. 2011; 11 (4): 405-13.

28. Oliveira MIC, Hartz ZMA, Silva KS. Avaliação da implantação da iniciativa hospital amigo da criança no Rio de Janeiro, Brasil. Rev Bras Saúde Matern Infant. 2012; 12 (3): 281-95
29. Araújo MFM, Otto AFN, Schmitz BAS. Primeira avaliação do cumprimento dos dez passos para o sucesso do aleitamento materno nos Hospitais Amigos da Criança do Brasil. Rev Bras Saúde Matern Infant. 2003; 3 (4): 411-9.

30. Sekya SR, Luz TR. Mudança organizacional: implantação da Iniciativa Hospital Amigo da Criança. Ciênc Saúde Coletiva. 2010; 15 (Supl. 1): 1263-73.

Received on September 15, 2017

Final version presented on June 03, 2018

Approved on July 16, 2018 